\title{
PENGARUH NITROGEN TERHADAP KUALITAS BERAS AROMATIK
}

\author{
The Effect of Nitrogen on the Quality of Aromatic Rice \\ Chairunnisak $^{a^{*},}$, Sugiyanta ${ }^{\mathrm{b}}$, Edi Santosa ${ }^{\mathrm{b}}$

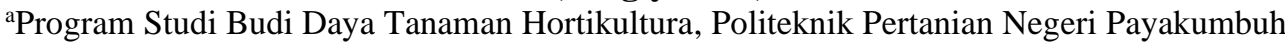 \\ Jl. Raya Negara KM.7 Tanjung Pati, Sumatera Barat 26271, Indonesia \\ ${ }^{b}$ Staf Pengajar Departemen Agronomi dan Hortikultura, Fakultas Pertanian, IPB University \\ Jl. Raya Dramaga, Kampus IPB Dramaga, Bogor 16680, Indonesia \\ *Email korespondensi: Agtnissa@gmail.com
}

Diterima 1 Maret 2021/Disetujui 25 April 2021

\begin{abstract}
ABSTRAK
Kualitas beras adalah hal penting yang dipertimbangkan oleh konsumen ketika membeli beras. Kualitas meliputi beberapa aspek, antara lain kualitas mutu giling dan mutu tanak. Tujuan penelitian adalah untuk mengetahui kualitas beras yang dihasilkan oleh padi aromatik pada perlakuan lima taraf dosis pupuk nitrogen (N). Penelitian menggunakan rancangan acak kelompok petak terbagi untuk menguji pengaruh dosis dan varietas. Petak utama adalah pupuk nitrogen pada berbagai dosis, yaitu: $0,45,90,135$ dan $180 \mathrm{~kg} \mathrm{~N}^{-1}$, dan anak petak adalah dua varietas padi aromatik yaitu Sigupai Abdya (lokal Aceh) dan Inpari 23 Bantul (unggul nasional). Kualitas beras aromatik (mutu giling dan mutu tanak) pada penelitian ini tidak dipengaruhi oleh dosis pupuk nitrogen, tetapi hanya dipengaruhi oleh varietas. Berdasarkan mutu giling, varietas Sigupai Abdya memiliki rendemen beras giling dan beras kepala lebih tinggi serta persentase beras menir lebih rendah dibandingkan dengan varietas Inpari 23 Bantul. Berdasarkan mutu tanak, varietas Inpari 23 Bantul memiliki kandungan amilosa yang rendah, sedangkan waktu layak makan nasi lebih lama diperoleh pada varietas Sigupai Abdya.
\end{abstract}

Kata kunci: amilosa, Inpari 23 Bantul, Sigupai Abdya, rendemen beras

\begin{abstract}
The quality of rice is one of the important things that consumers consider when buying rice. The quality of rice consists of several aspects, including the milling quality and cooking quality. This study aims to determine the quality of rice produced by aromatic rice in the treatment of five levels of nitrogen fertilizer $(N)$ doses. This research was conducted in a split plot randomized block design to examine the effect of dose and variety. The dosage of $N$ fertilizer as the main plot consists of five levels, namely: 0, 45, 90, 135 and $180 \mathrm{~kg} \mathrm{~N} \mathrm{ha-1,} \mathrm{and} \mathrm{two}$ varieties of aromatic rice as subplots, namely: Sigupai Abdya (local Aceh) and Inpari 23 Bantul (national superior). The quality of aromatic rice (milling quality and cooking quality) in this study was not influenced by nitrogen fertilizer dosage but only by variety. Based on the milling quality, the Sigupai Abdya variety has higher milled rice percentage and head rice percentage and has lower drop rice percentage compared with Inpari 23 Bantul. Based on cooking quality, variety Inpari 23 Bantul has a low amylose content, while the longer time to eat rice was obtained in the Sigupai Abdya variety.
\end{abstract}

Keywords: amylose, Inpari 23 Bantul, Sigupai Abdya, rice rendemen

\section{PENDAHULUAN}

Beras merupakan sumber makanan dan nutrisi serta salah satu produk pertanian yang paling penting dan dibudiyakan hampir di seluruh dunia (de Miranda et al. 2015). Tantangan agribisnis pada budidaya tanaman padi untuk penyediaan beras di masa mendatang tidak hanya berfokus pada aspek peningkatan produksi, tetapi juga pada aspek kualitas beras yang dihasilkan, karena dengan bertambahnya pendapatan masyarakat maka konsumen beras mulai tersegmentasi berdasarkan berbagai kualitas beras (Nurmalina et al. 2012). Beras yang berkualitas tinggi dapat dihasilkan dari proses pengolahan yang baik atau dari 
varietas yang memiliki cita rasa dan karakteristik tertentu. Beras aromatik mulai disukai oleh konsumen karena memiliki aroma dan cita rasa yang khas. Hasil penelitian Nurjaya dan Maulida (2018) pada beras aromatik Pandan Wangi murni Cianjur menunjukkan bahwa varietas tersebut banyak disukai oleh masyarakat setempat karena aroma yang khas. Indonesia memiliki tingkat keanekaragaman varietas padi aromatik yang cukup tinggi. Salah satu padi aromatik yang memiliki petensi untuk dikembangkan adalah varietas Sigupai Abdya yang merupakan padi unggul lokal asal Aceh.

Salah satu komponen penting dalam budidaya tanaman padi adalah pemupukan. Pertumbuhan tanaman akan baik dan diperoleh hasil yang optimum apabila nutrisi tersedia dengan cukup dan dapat diserap oleh tanaman. Ketersediaan nutrisi yang terbatas akan menyebabkan penurunan pertumbuhan dan produksi tanaman. Menurut Bustami et al. (2012), pemupukan bertujuan untuk menambah atau mempertahankan kesuburan tanah, yang ditinjau dari segi ketersediaan hara di dalam tanah secara cukup dan berimbang, baik hara makro maupun mikro. Jenis pupuk yang sebagian besar digunakan dalam pertanian modern saat ini untuk meningkatkan hasil panen adalah pupuk kimia (Rei et al. 2014), terutama urea, sebagai sumber nitrogen. Nitrogen merupakan hara yang sangat diperlukan dalam produksi tanaman padi karena berpengaruh signifikan terhadap hasil dan kualitas gabah (Zhu et al. 2017). Nitrogen dapat meningkatkan kualitas gabah seperti menambah ukuran gabah (Patti et al. 2013), meningkatkan mutu giling (beras pecah kulit, persentase beras giling, dan persentase beras kepala), mutu tampilan (persentase beras mengapur, ukuran kapur dan pengapuran) dan mutu tanak (kandungan amilosa, konsistensi gel, puncak visikositas, kerusakan dan kemunduran ( $\mathrm{Gu}$ et al. 2015).

\section{MATERI DAN METODE}

\section{Waktu dan Tempat}

Penelitian dilakukan pada bulan November 2017 - April 2018 di Kebun Percobaan Babakan Sawah Baru IPB University, Dramaga, Bogor. Analisis mutu beras dilakukan di Balai Penelitian Muara, Bogor.

\section{Alat dan Bahan}

Alat yang digunakan meliputi alat pengolah tanah, timbangan, sprayer, alat panen, alat perontok padi, penggilingan padi dan alat-alat laboratorium. Bahan yang digunakan yaitu benih padi, pupuk (Urea, SP-36, dan $\mathrm{KCl}$ ), gabah padi, beras, etanol, $\mathrm{NaOH}, \mathrm{I}_{2}$, asam asam asetat, larutan alkali, dan air.

\section{Rancangan Percobaan dan Perlakuan}

Penelitian menggunakan rancangan perlakuan petak terbagi (Split Plot Design) dalam rancangan acak kelompok (RAK) yang terdiri atas tiga ulangan. Faktor pertama sebagai petak utama yaitu dosis pupuk nitrogen : $0 \mathrm{~kg} \mathrm{~N}^{-1}\left(\mathrm{~N}_{0}\right), 45 \mathrm{~kg} \mathrm{~N}$ $\mathrm{ha}^{1}\left(\mathrm{~N}_{1}\right), 90 \mathrm{~kg} \mathrm{~N}^{-1}\left(\mathrm{~N}_{2}\right), 135 \mathrm{~kg} \mathrm{~N}^{-1}$ $\left(\mathrm{N}_{3}\right)$, dan $180 \mathrm{~kg} \mathrm{~N} \mathrm{ha}^{-1}\left(\mathrm{~N}_{4}\right)$. Faktor kedua sebagai anak petak adalah padi lokal Aceh varietas Sigupai Abdya $\left(\mathrm{V}_{1}\right)$ dan padi unggul nasional varietas Inpari 23 Bantul $\left(\mathrm{V}_{2}\right)$. Varietas Inpari 23 Bantul merupakan varietas pembanding.

\section{Pelaksanaan Penelitian}

Penelitian terdiri atas dua tahapan, yaitu tahap penanaman (budidaya) dan tahap analisis mutu beras. Budidaya tanaman padi dimulai dari pengolahan tanah sawah, persemaian, penanaman, pengendalian hama dan penyakit, pemupukan (sesuai dengan perlakuan) dan pemanenan. Padi yang telah dipanen selanjutnya dilakukan perontokan dan penggilingan sehingga didapatkan gabah dan beras untuk alisis mutu.

\section{Pengamatan}

Peubah yang diamati pada mutu beras adalah mutu giling dan mutu tanak. 
Mutu giling meliputi kadar air gabah kering giling (GKG), rendemen beras giling, rendemen beras kepala, perentase beras patah, dan persentase beras menir. Kadar air gabah kering giling diukur dengan alat green mouisture tester. Rendemen beras giling, persentase beras kepala, persentase beras patah dan beras menir diperoleh dari perhitungan sebagai berikut:

Randemen $=\frac{\text { bobot beras giling (output) }}{\text { bobot gabah (input) }} \times 100 \%$

Beras kepala $=\frac{\text { bobot beras kepala }(\mathrm{g})}{\text { bobot beras giling }(\mathrm{g})} \times 100 \%$

Beras patah $=\frac{\text { beras patah }(\mathrm{g})}{\text { bobot sampel }(\mathrm{g})} \times 100 \%$

Beras menir $=\frac{\text { bobot beras menir }(\mathrm{g})}{\text { bobot beras giling }(\mathrm{g})} \times 100 \%$

Mutu tanak meliputi kadar amilosa, suhu gelatinisasi, nisbah penyerapan air (WUR) dan waktu layak makan nasi. Cara pengukuran kadar amilosa yaitu $100 \mathrm{mg}$ tepung beras dimasukkan ke dalam labu ukur $100 \mathrm{ml}$, lalu tuangkan $1 \mathrm{ml}$ etanol 95\% dan $9 \mathrm{ml} \mathrm{NaOH} 1 \mathrm{~N}$. Larutan tersebut didiamkan pada suhu ruang selama 23 jam, dan diencerkan menggunakan air suling hingga menjadi $100 \mathrm{ml}$. Sebanyak $5 \mathrm{ml}$ larutan tersebut dipipet dan dimasukkan ke dalam labu ukur $100 \mathrm{ml}$ yang berisi $60 \mathrm{ml}$ air, serta $1 \mathrm{ml}$ asam asetat $1 \mathrm{~N}$ dan $2 \mathrm{ml} \mathrm{I}_{2}$ $2 \%$, kemudian diencerkan sampai volume $100 \mathrm{ml}$. Larutan tersebut selanjutnya dikocok, didiamkan 20 menit dan dilakukan pengukuran absorbannya dengan menggunakan spektrofotometer dengan panjang gelombang $620 \mathrm{~nm}$ (Aliawati, 2003). Suhu gelatinisasi beras menunjukkan lamanya waktu yang diperlukan untuk memasak beras menjadi nasi. Perendaman beras dalam larutan alkali merupakan metode yang digunakan dalam penentuan sifat suhu gelatinisasi, kemudian tingkat kerusakannya diukur dengan pemberian skor/nilai kerusakan 17. Nilai 1-3 tergolong tinggi dengan suhu $>74{ }^{\circ} \mathrm{C}$, nilai $4-5$ tergolong sedang dengan suhu $70-74{ }^{\circ} \mathrm{C}$, dan nilai 6-7 tergolong rendah dengan suhu $70{ }^{\circ} \mathrm{C}$ (Suismono et al. 2003).

Nisbah penyerapan air nasi (WUR/water uptake rasio) adalah perbandingan bobot nasi dengan bobot beras yang dimasak, dihitung dengan rumus:

$$
\mathrm{NPA}=\frac{\text { bobot nasi-kurang beras }}{\text { bobot beras }} \times 100 \%
$$

Lama waktu layak makan dihitung dari lamanya waktu nasi sampai basi/busuk. Nasi yang telah matang dibiarkan dalam suhu ruang sampai nasi menjadi basi.

\section{Analisis Data}

Analisis data menggunakan sidik ragam (ANOVA), jika perlakuan berpengaruh nyata dilakukan uji beda nilai tengah respon antar taraf menggunakan Duncan multiple range test (DMRT) pada taraf nyata 5\%. Pengolahan data menggunakan software SAS.

\section{HASIL DAN PEMBAHASAN}

\section{Mutu giling}

Kualitas beras ditentukan oleh beberapa faktor, salah satunya adalah mutu giling. Mutu giling meliputi rendemen beras giling, rendemen beras kepala, persentase beras patah, dan persentase beras menir. Beras kepala, beras patah, dan beras menir dibedakan berdasarkan ukuran butiran beras. Berdasarkan SNI 2015 spesifikasi persyaratan mutu beras disajikan pada Tabel 1.

Data hasil penelitian, kualitas mutu giling beras varietas Sigupai Abdya dan Inpari 23 Bantul akibat pemberian pupuk $\mathrm{N}$ pada berbagai dosis disajikan pada Tabel 2. 
Tabel 1. Spesifikasi persyaratan mutu beras SNI 6128:2015

\begin{tabular}{llccccc} 
& & & \multicolumn{4}{c}{ Kelas mutu } \\
\cline { 4 - 6 } No & Komponen mutu & Satuan & \multirow{2}{*}{ Premium } & \multicolumn{3}{c}{ Medium } \\
\cline { 4 - 6 } & & & 100 & 95 & 90 & 80 \\
2 & Derajat sosoh (min) & $(\%)$ & 14 & 14 & 14 & 15 \\
2 & Kadar air (maks) & $(\%)$ & 95 & 78 & 73 & 60 \\
3 & Beras kepala (min) & $(\%)$ & 5 & 20 & 25 & 35 \\
4 & Butir patah (maks) & $(\%)$ & 0 & 2 & 2 & 5 \\
5 & Butir menir (maks) & $(\%)$ & 0 & 2 & 3 & 3 \\
6 & Butir merah (maks) & $(\%)$ & 0 & 2 & 3 & 5 \\
7 & Butir kuning/rusak (maks) & $(\%)$ & 0 & 2 & 3 & 5 \\
8 & Butir kapur (maks) & $(\%)$ & 0 & 0.02 & 0.05 & 0.2 \\
9 & Benda asing (maks) & (Butir/100 g) & 0 & 1 & 2 & 3 \\
10 & Butir gabah (maks) & & & & &
\end{tabular}

Sumber : BSN (2015)

Hasil penelitian diperoleh bahwa aplikasi pupuk $\mathrm{N}$ pada berbagai dosis tidak berpengaruh terhadap kadar air gabah kering giling, rendemen beras giling, rendemen beras kepala, persentase beras patah, dan persentase beras menir.
Perlakuan yang berpengaruh hanyalah varietas. Faktor yang menyebabkan tidak berpengaruhnya perlakuan pupuk $\mathrm{N}$ pada berbagai dosis diduga karena curah hujan yang tinggi selama penelitian.

Tebel 2. Kualitas mutu giling beras pada berbagai perlakuan dosis $\mathrm{N}$ dan varietas

\begin{tabular}{|c|c|c|c|c|c|}
\hline Perlakuan & $\begin{array}{l}\text { Kadar air } \\
\text { GKG }(\%)\end{array}$ & $\begin{array}{l}\text { Rendemen } \\
\text { beras giling } \\
(\%)\end{array}$ & $\begin{array}{c}\text { Rendemen } \\
\text { beras kepala } \\
(\%)\end{array}$ & $\begin{array}{c}\text { Persentase } \\
\text { beras patah } \\
\quad(\%)\end{array}$ & $\begin{array}{l}\text { Persentase } \\
\text { beras menir } \\
(\%)\end{array}$ \\
\hline \multicolumn{6}{|l|}{ Dosis N $\left(\mathrm{kg}^{-1}\right)$} \\
\hline 0 & 13,45 & 62,77 & 65,66 & 14,16 & 20,16 \\
\hline 45 & 13,80 & 57,83 & 67,83 & 15,66 & 16,50 \\
\hline 90 & 13,76 & 60,83 & 72,16 & 12,83 & 15,00 \\
\hline 135 & 13,73 & 64,16 & 68,66 & 13,00 & 17,33 \\
\hline 180 & 13,90 & 60,72 & 66,83 & 13,50 & 20,00 \\
\hline \multicolumn{6}{|l|}{ Varietas } \\
\hline Sigupai Abdya & 13,71 & $64,62^{\mathrm{a}}$ & $71,66^{\mathrm{a}}$ & 14,20 & $14,13^{\mathrm{b}}$ \\
\hline Inpari 23 Bantul & 13,74 & $57,91^{\mathrm{b}}$ & $64,80^{\mathrm{b}}$ & 13,46 & $21,46^{\mathrm{a}}$ \\
\hline Interaksi & tn & tn & tn & tn & tn \\
\hline
\end{tabular}

\section{Kadar air Gabah Kering Giling (GKG)}

Kadar air gabah yaitu kandungan air dalam butiran gabah yang dapat dinyatakan dalam persen (Iswanto et al. 2018). Faktor yang menentukan kualitas beras salah satunya adalah kadar air gabah. Kandungan air pada gabah jika terlalu rendah atau tinggi akan mempengaruhi hasil penggilingan gabah, sehingga menyebabkan beras menjadi rusak (mudah patah). Menurut BSN (2015) kadar air gabah maksimum adalah 14\%. Kadar air pada gabah yang baru saja dipanen pada umumnya adalah lebih dari 14\%, sehingga untuk menurunkan kadar air dilakukan pengeringan dengan cara menjemur langsung dibawah sinar matahari. Hasil pengukuran rata-rata kadar air gabah pada varietas Sigupai tidak berbeda nyata dengan Inpari 23 Bantul setelah dikeringkan yaitu $13,71 \%$ dan $13,74 \%$. Menurut Umar (2011) kadar air yang 
optimum untuk gabah kering giling yaitu 13\%-14\%. Kadar air gabah pada kedua varietas ini sudah bisa digolongkan ke dalam kategeri layak untuk dilakukan penggilingan.

\section{Rendemen Beras Giling}

Rendemen beras giling adalah bobot beras giling yang diperoleh dari proses penggilingan gabah. Varietas Sigupai Abdya menghasilkan rendemen beras giling $6.71 \%$ lebih tinggi dari Inpari 23 Bantul, hal ini diduga terjadi karena perbedaan varietas yang digunakan. Menurut Dewayani et al. (2009) varietas adalah salah satu faktor yang berpengaruh langsung terhadap rendemen giling. Hal ini juga didukung oleh Winarno (2004), bahwa bahan mentah gabah, varietas, derajat kematangan, cara penanganan awal (prehandling) dan tipe mesin penggiling berpengaruh terhadap rendemen giling. Hal lain yang mempengaruhi hasil rendemen beras giling adalah penyosohan beras. Menurut Tharir (1996) Ketika proses penyosohan berlangsung banyak bagian beras yang menjadi dedak karena adanya gesekan dan tekanan sehingga mengakibatkan rendemen beras giling yang dihasilkan menjadi rendah. Hasbullah dan Dewi (2009) juga menambahkan bahwa kinerja mesin-mesin yang dipakai dalam proses penggilingan mempengaruhi rendemen beras giling.

\section{Rendemen Beras Kepala}

Rendemen beras kepala menentukan kualitas fisik beras giling. semakin tinggi persentase beras kepala maka kualitas fisik beras giling akan semakin meningkat. Rendemen beras kepala yang lebih tinggi (71,66\%) dihasilkan oleh varietas Sigupai Abdya, sedangkan yang dihasilkan oleh varietas Inpari 23 Bantul hanya sebesar $64.80 \%$. Rendemen beras kepala varietas Sigupai Abdya dan Inpari 23 Bantul tergolong ke dalam kelas mutu medium 3 (BSN, 2015). Menurut Nugraha dan tim (2011), kegiatan pascapanen yang terdiri atas waktu panen, cara panen, alat perontok, pengeringan, serta cara penggilingan mempengaruhi persentase beras yang dihasilkan. Faktor penyebab rendahnya rendemen beras kepala pada penelitian ini diduga karena faktor alat penggiling. Penggilingan padi menggunakan alat penggiling kecil. Hasil penelitian Ulfa et al. (2014) juga menunjukkan bahwa penggilingan padi besar menghasilkan persentase beras kepala yang lebih tinggi dibandingkan dengan penggilingan padi kecil.

\section{Persentase Beras Patah dan Beras menir}

Kualitas beras akan rendah apabila persentase beras patah dan beras menir tinggi. Varietas Sigupai Abdya dan Inpari 23 Bantul mengahasilkan persentase beras patah yang tidak berbeda nyata antara keduanya. Persentase beras menir terendah ditemui pada varietas Sigupai Abdya $(14,13 \%)$ sehingga dapat dikatakan bahwa Sigupai Abdya mempunyai mutu yang lebih baik dibanding Inpari 23 Bantul. Tingginya persentase beras patah dan menir dalam hal ini diduga karena faktor kadar air gabah dan penyosohan. Kadar air GKG kedua varietas ini adalah dibawah $14 \%$, akibatnya butiran gabah mudah retak sehingga ketika digiling menyebabkan tingginya persentase beras patah dan beras menir. Hal ini didukung oleh hasil penelitian Indrasari et al. (2009) yaitu gabah pada kadar air 14\%-15\% akan diperoleh hasil penggilingan yang optimal. Beras putih diperoleh dari proses penyosohan. Proses penyosohan dapat menyebabkan tingginya jumlah beras patah dan menir, karena pada proses penyosohan yang terlalu lama bulir beras menjadi tipis dan suhu penggilingan meningkat, sehingga beras akan mudah patah dan pecah (Ulfa et al. 2014).

\section{Mutu tanak}

Dosis $\mathrm{N}$ tidak mempengaruhi suhu gelatinisasi, kadar amilosa, nisbah penyerapan air dan waktu layak makan makan nasi, sedangkan perlakuan varietas berpengaruh nyata terhadap suhu 
gelatinisasi, kadar amilosa, dan waktu layak makan nasi. Tidak ada pengaruh interaksi nyata antara dosis $\mathrm{N}$ dan varietas yang dicobakan (Tabel 3).

Tabel 3. Kualitas mutu tanak beras pada berbagai perlakuan dosis $\mathrm{N}$ dan varietas

\begin{tabular}{|c|c|c|c|c|}
\hline Perlakuan & $\begin{array}{c}\text { Kadar amilosa } \\
(\%)\end{array}$ & $\begin{array}{c}\text { Suhu } \\
\text { gelatinisasi }\end{array}$ & $\begin{array}{c}\text { Nisbah penyerapan } \\
\text { air }(\%)\end{array}$ & $\begin{array}{c}\text { Waktu layak makan } \\
\text { nasi (jam) }\end{array}$ \\
\hline \multicolumn{5}{|l|}{ Dosis N $\left(\mathrm{kg}^{-1}\right)$} \\
\hline 0 & 19,53 & 4 & 179,66 & 25,43 \\
\hline 45 & 18,90 & 4 & 173,50 & 25,20 \\
\hline 90 & 19,30 & 3 & 177,33 & 25,20 \\
\hline 135 & 19,40 & 4 & 178,00 & 25,20 \\
\hline 180 & 19,03 & 3 & 169,16 & 26,03 \\
\hline \multicolumn{5}{|l|}{ Varietas } \\
\hline Sigupai Abdya & $20,92^{\mathrm{a}}$ & $1^{\mathrm{b}}$ & 173,26 & $27,00^{\mathrm{a}}$ \\
\hline Inpari 23 Bantul & $17,54^{\mathrm{b}}$ & $6^{\mathrm{a}}$ & 177,80 & $23,78^{\mathrm{b}}$ \\
\hline Interaksi & tn & tn & tn & tn \\
\hline
\end{tabular}

Kadar amilosa yang lebih tinggi, suhu gelatinisasi yang lebih rendah, serta waktu layak makan yang lebih lama diperoleh pada varietas Sigupai Abdya. Tingkat kekerasan dan kelengketan nasi ditentukan oleh kadar amilosa. Semakin rendah kadar amilosa maka nasinya akan semakin pulen/lengket. Menurut Sattari (2015) kadar amilosa pada beras terbagi tiga, yaitu (1) tinggi (>25\%: umumnya adalah padi indica, nasi yang dihasilkan kering saat dimasak dan menjadi keras setelah dingin). (2) rendah (15\%-20\%: nasi yang dihasilkan pulen dan lengket, mencakup semua kultivar japonica. (3) sedang (20\%-25\%: nasi yang dihasilkan pulen tetapi tidak lengket, dan secara luas disukai oleh sebagian besar konsumen). Berdasarkan pengolongan tersebut diperoleh bahwa Sigupai Abdya termasuk ke dalam beras dengan kadar amilosa sedang (20.92\%), dan beras Inpari 23 Bantul adalah beras dengan kadar amilosa rendah (17.54\%).

Suhu gelatinisasi adalah bagian penting lainnya yang mempengaruhi mutu tanak beras. Suhu gelatinisasi merupakan suatu kisaran suhu yang granula pati mulai mengembang secara permanen dalam air panas bersamaan dengan hilangnya bentuk kristal dari pati tersebut (Wibowo et al. 2009). Suhu gelatinisasi pada beras terdiri atas tiga katagori yaitu nilai/skor 1-3 dengan suhu lebih besar dari $74{ }^{0} \mathrm{C}$ termasuk ke dalam katagori tinggi, nilai/skor 4-5 dengan suhu $70-74{ }^{0} \mathrm{C}$ termasuk ke dalam katagori sedang, dan nilai/skor $70{ }^{0} \mathrm{C}$ termasuk ke dalam katagori rendah (Suismono et al. 2003). Kriteria suhu gelatinisasi varietas Sigupai Abdya adalah 1 serta Inpari 23 Bantul adalah 6, artinya suhu gelatinisasi yang dimiliki oleh beras Sigupai Abdya termasuk tinggi $\left(>74^{\circ} \mathrm{C}\right)$, sedangkan Inpari 23 Bantul termasuk rendah $\left(55-69^{\circ} \mathrm{C}\right)$.

Beras yang bersuhu gelatinisasi tinggi artinya butuh lebih banyak air dan juga waktu pemasakan yang lebih lama dibandingkan dengan beras yang bersuhu gelatinisasi rendah dan sedang (Hossain $e t$ al. 2009). Waktu layak makan nasi pada varietas Inpari 23 Bantul lebih singkat diduga karena tekstur nasi pada varietas ini lebih lembek dan lebih pulen dibandingkan dengan Sigupai abdya, hal ini dibuktikan dengan kandungan kadar amilosa pada kedua varietas tersebut. Kadar amilosa juga berhubungan dengan tingkat retrogradasi pati. Nasi yang mempunyai kadar amilosa rendah akan lambat beretrogradasi (Prima et al. 2015). Menurut Dreher et al. (1984) retrogradasi mengakibatkan pati menjadi lebih sulit dicerna oleh enzim. Nasi dari varietas 
Sigupai Abdya beretrograsi lebih cepat karena memiliki kadar amilosa lebih tinggi dibandingkan dengan Inpari 23 Bantul, sehingga diduga lebih tahan terhadap enzim yang berperan dalam proses pembusukan makanan.

Faktor lain yang mempengaruhi karakter beras secara umum adalah genetik dan lingkungan. Faktor genetik yang dimaksud beberapa diantaranya adalah ukuran dan bentuk, pengapuran (chalky), kandungan amilosa dan konsistensi gel, sedangkan faktor lingkungan di antaranya yaitu butir kuning rusak, butir retak dan kadar air (Wibowo et al. 2009).

\section{KESIMPULAN}

Kualitas beras aromatik (mutu giling dan mutu tanak) pada penelitian ini

\section{DAFTAR PUSTAKA}

Aliawati G. 2003. Teknik analisis kadar amilosa dalam beras. Buletin Teknik Pertanian. 8(2):82-84.

[BSN] Badan Standardisasi Nasional. 2015. Beras. Jakarta: BSN.

Bustami, Sufardi, Bakhtiar. 2012. Serapan hara dan efisiensi pemupukan phosfat serta pertumbuhan padi varietas lokal. JMSDL. 1(2):159-170.

De Miranda MS, Fonseca ML, Lima A, de Moraes TF, Rodrigues FA. 2015. Environmental impacts of rice cultivation. American Journal of Plant Sciences. 6: 2009-2018.

Dewayani W, Darmawidah A, Razak N, Baco D. 2009. Pengaruh jenis alat giling dan varietas terhadap kualitas beras di Sulawesi Selatan. Jurnal Pengkajian dan Pengembangan Teknologi Pertanian. 12:1-10.

Dreher ML, Dreher CJ, Berry JW. 1984. Starch digestibility of foods: Nutritional perspective. Critical review in food science and nutrion. CRC Press Inc. 20:47-71. tidak dipengaruhi oleh dosis pupuk nitrogen, tetapi hanya dipengaruhi oleh varietas. Berdasarkan mutu giling, varietas Sigupai Abdya memiliki rendemen beras giling dan beras kepala lebih tinggi serta persentase beras menir lebih rendah dibandingkan dengan varietas Inpari 23 Bantul. Berdasarkan mutu tanak, varietas Inpari 23 Bantul memiliki kandungan amilosa yang rendah, sedangkan waktu layak makan nasi lebih lama diperoleh pada varietas Sigupai Abdya.

\section{UCAPAN TERIMA KASIH}

Penulis mengucapkan terima kasih kepada pihak yang telah mendanai penelitian ini yaitu Lembaga Pengelola Dana Pendidikan (LPDP) Republik Indonesia.

Gu J, Chen J, Chen L, Wang Z, Zhang H, Yang J. 2015. Grain quality changes and responses to nitrogen fertilizer of japonica rice cultivated released in the Yangtz River Basin from the 1950s to 2000s. The Crop Journal. 3: 285-297.

Hasbullah R, Dewi AR. 2009. Kajian pengaruh konfigurasi mesin penggilingan terhadap rendemen dan susut giling beberapa varietas padi. JTEP. 23(2):1-6

Hossain MS, Singh AK, Zaman F. 2009. Cooking and eating characteristics of some newly identified inter subspecific (indica/japonica) rice hybrids. Sci Asia. 35: 320-325.

Indrasari SD, Purwani EY, Widowati S, Damardjati DS. 2009. Peningkatan nilai tambah beras melalui mutu fisik, cita rasa dan gizi. [Online]. [Diunduh pada 2017 Feb 22].Tersedia pada:htttp://www.lit bang.pertanian.go.id/special/padi/bbp adi2009_itp_21.pdf.

Iswanto PH, Akbar ARM, Rahmi A. 2018. Pengaruh kadar air gabah terhadap mutu beras pada varietas padi lokal 
siam sabah. JTAM Inovasi Agroindustri. 1(1): 12-23.

Nurjaya, Maulida N. 2018. Tingkat kesukaan konsumen pada atribut beras pandan wangi murni Cianjur. Agroscience. 8(1): 1-15.

Nurmalina R, Rachmina D, Sumedi, Novianti T. 2012. Efisiensi Produksi dan Pemasaran Padi Pandan Wangi. Bogor (ID): Departemen Agribisnis Fakultas Ekonomi dan Manajemen Institut Pertanian Bogor.

Patti PS, Kaya E, Silahooy Ch. 2013. Analisis status nitrogen tanah dalam kaitannya dengan serapan oleh tanaman padi sawah di Desa Waimital, Kecamatan Kairatu, Kabupaten Seram Bagian Barat. Agrologia. 2(1): 51-58.

Prima L, Heti H, Widowati S, Priyanto AB. 2015. Pengaruh kandungan amilosa terhadap karakteristik fisik dan organoleptik nasi instan. Journal Penelitian Pascapanen Pertanian. 12(1): 1-10.

Rei N, Priyanka A, Rathore DS. 2014. Comparative Study of the effect of chemical fertilizers and organic fertilizers on eisenia foetida. Ijirset. 3(5):12991-12998.

Sattari A, Mahdinezhad N, Fakheri B, Noorozi M, Baheshtizadeh H. 2015. Improvement of the eating and cooking qualities of rice. Intl J Farm \& Alli Sci. 4:153-160.

Suismono, Setyono A, Indrasari SD, Wobowo P, Las I. 2003. Evauasi mutu beras berbagai varietas padi di Indonesia. Sukamandi (ID): Balai Penelitian Tanaman Padi.

Thahir R. 1996. Effect of various polishing types on rice milling quality. International Seminar on Recent Development on Agricultural Machinery for Postharvest Handling of Rice, Surabaya.

Ulfa R, Hariyadi P, Muhandri T. 2014. Rendemen giling dan mutu beras pada beberapa unit penggiling padi kecil keliling di Kabupaten Banyuwangi. Jurna lmutu pangan. 1(1): $26-32$.

Umar S. 2011. Pengaruh sistim penggilingan padi terhadap kualitas giling di sentra produksi beras lahan pasang surut. Jurnal Teknologi Pertanian. 7(1): 9-17.

Wibowo P, Indrasari SD, Jumali. 2009. Identifikasi karakteristik dan mutu beras di Jawa Barat. PPTP. 28(1):4349.

Winarno FG. 2004. GMP dalam industri penggilingan padi. Prosiding Lokakarya Nasional Upaya Peningkatan Nilai Tambah Pengolahan Padi. Jakarta.

Zhu DW, Zhang HC, Guo BW, Xu K, Dai QG, Wei HY, Gao H, Hu YJ, Cui PY, Huo ZY. 2017. Effects of nitrogen level on yield and quality of japonica soft super rice. Journal of Integrative Agriculture. 16(5):10181027. 